\title{
Medical Resource Sharing Under Background of Information Technology
}

\author{
Cheng Juandai, a , Liang Changyong ${ }^{2, b}$ and Shu Jian ${ }^{3, c}$ \\ School of Management, Hefei University of Technology, Hefei 230009, China \\ shujian9@163.com
}

Keywords: Medical Information, Resource Integration, Information Sharing.

\begin{abstract}
Disequilibrium and ineffective is a common and long-term contradiction existed in Chinese medical resource area. However, the new healthcare reform, application of information technology and arising of smart health give new ideas to solve this problem, as healthcare reform offer political and financial support and information technology provide a new channel to share resource in different areas and levels. To find a way to balance medical resource in our country, we have interviewed leaders in hospital and other medical establishments, reviewed document information and consulted medium news. We analysis political barriers and technological obstacle and finally give proposal to the distribution and construction of medical and medical information resource.
\end{abstract}

\section{Introduction}

Since 2009 the State Council and National Health and Family Planning Commission (SCNHFPC) has successively issued several policy document, for the purpose of guiding and standardizing the developing and revolution of Chinese medical and health. The reform aims at improving the equality, accessibility and convenience of people`s medical-seeking pattern and reducing medical costs. However, as the reform advancing, there explores the systematic and structural contradiction hidden in deep. Disequilibrium of the medical resource is one of the tough problems.

After comprehensive analysis of our new health policies, we found many directions to help balance the resource allocation, such as the dual referral system, grading therapy, medical consortium in cities, tele-medicine in remote area. Besides, the "36312 project" aroused by SCNHFPC, aimed at sharing medical information in the whole country, is a basic engineering for optimizing resource distribution. All these measures mean to allocate medical service and resource to remote and rural area. In spite of this, our country under the condition of vast landmass with large population, and medical information developed in different levels, speed and aim during various area and medical establishment. Thus, sharing medical resource in administrative regions or through the whole country with tools of information technology is still an arduous task. In paper we analysis influence factors such as policies, medical-seeking patterns and development mode of medical information, and then propose suggestion for optimizing medical resource allocation.

\section{Present Situation of Medical Resource Allocation}

Resource distribution in our country appeared in the mode of "inverted triangle", which shows not only between urban and rural but also between cities of different size and economy, and also in different medical establishments in one city. That means, generally, richer areas get richer resource and poorer areas have poorer resource.

\section{Resource distribution in different areas}

We selected indexes as total assets of medical establishments in the whole area, amount of tertiary-level hospitals and health workers per thousand people enjoy. 
Table 1. Comparison of Medical Resource in Eastern, Middle and Western area

\begin{tabular}{|c|c|c|c|c|c|c|c|c|c|}
\hline \multirow{2}{*}{ Year } & \multicolumn{3}{|c|}{$\begin{array}{c}\text { Total assets in medical } \\
\text { establishments[mil] }\end{array}$} & \multicolumn{3}{c|}{$\begin{array}{c}\text { Amount of tertiary-level } \\
\text { hospitals[pce] }\end{array}$} & \multicolumn{3}{c|}{$\begin{array}{c}\text { health workers per thousand } \\
\text { people }\end{array}$} \\
\cline { 2 - 12 } & East & Middle & West & East & Middle & West & East & Middle & West \\
\hline 2010 & 967651 & 421492 & 372193 & 585 & 359 & 314 & 5.22 & 3.93 & 3.76 \\
\hline 2011 & 1110349 & 523962 & 451115 & 627 & 385 & 338 & 5.49 & 4.04 & 4.00 \\
\hline 2012 & 1099369 & 558925 & 496607 & 726 & 443 & 389 & 5.33 & 4.65 & 4.71 \\
\hline
\end{tabular}

Data source: China Health Statistics Annual of 2013

From the table we can find in China eastern area enjoys more resource than middle area, and middle area is superior to western area. The first reason for this situation is that economically advanced area enjoys more funding from local government. The second reason is production factors swarmed into eastern area rapidly since reform and opening. The third reason is we evaluate resource distribution by amount of resource per thousand people enjoy and then allocate resource without regarding of geographic factors, which leads to western area---area enjoy lower population densities, obtain less resource from the government [1].

\section{Resources distribution within an area}

(1)Urban and rural

We select indexes as health expenses, health workers per thousand people enjoy, amount of beds in hospital per thousand people enjoy to compare resource distribution in urban and rural.

Table 2. Comparison of medical resource in urban and rural

\begin{tabular}{|c|c|c|c|c|c|c|c|c|c|}
\hline \multirow[t]{2}{*}{ Year } & \multicolumn{3}{|c|}{ Health expenses per person (Yuan) } & \multicolumn{3}{|c|}{$\begin{array}{l}\text { Health workers per thousand } \\
\text { people }\end{array}$} & \multicolumn{3}{|c|}{$\begin{array}{l}\text { Amount of beds in hospital per } \\
\text { thousand people (pcs) }\end{array}$} \\
\hline & Urban & Rural & Ration & Urban & Rural & Ration & Urban & Rural & Ration \\
\hline 2010 & 2315.5 & 666.3 & $28.77 \%$ & 7.62 & 3.04 & $39.9 \%$ & 5.94 & 2.60 & $43.77 \%$ \\
\hline 2011 & 2697.5 & 879.4 & $32.6 \%$ & 6.68 & 2.66 & $39.82 \%$ & 6.24 & 2.80 & $44.87 \%$ \\
\hline 2012 & 2969 & 1055.9 & $35.56 \%$ & 8.54 & 3.41 & $39.93 \%$ & 6.88 & 3.11 & $45.2 \%$ \\
\hline
\end{tabular}

Data source: China Health Statistics Annual of 2013

From the table we can find there is a huge gap between rural area and urban area on medical resource allocation.

(2)Different regions in an area

Zhang Nan(2014) has analyzed health resource equalities with Theil index, and find that larger regional gap exist within eastern area than within western or middle area. The reason is that health development is focused on the most economical advanced cities, with ignoring or even sacrificing benefits of surrounding cities [2]. Han Xuemei(2013) find in western area health resource concentrate in regions with dense population[3].

\section{Sharing Mechanism for Medical Resource}

As the medical resource disequilibrium is caused by political system, economy, level of technology and consumption habit of patient, it is difficult to overcome long-term inner contradiction by government deploy in the short run. New medical model under ground of 
information technology provide an approach to relieve this contradiction by sharing medical resource. We summarized sharing approach wide used in our country as follows:

Table 3. Medical resource sharing model and means

\begin{tabular}{|c|c|c|c|}
\hline & Term & Definition & Characteristic \\
\hline \multirow[b]{2}{*}{ Model } & $\begin{array}{l}\text { Health } \\
\text { Alliance }\end{array}$ & $\begin{array}{l}\text { Hospital in different types or } \\
\text { levels ally together to be a } \\
\text { community of interests. }\end{array}$ & $\begin{array}{l}\text { Usually take tertiary or second-class hospitals as } \\
\text { leaders, the alliance can be loose or tightly-knit } \\
\text { type. There are models as follow: Medical Group, } \\
\text { Hospital Trusteeship, Asset Restructuring, } \\
\text { Healthcare Collaboration and others. }\end{array}$ \\
\hline & $\begin{array}{l}\text { Family } \\
\text { medical }\end{array}$ & $\begin{array}{l}\text { A patient-oriented model, which } \\
\text { based on information technology, } \\
\text { aimed at establishing strong } \\
\text { primary healthcare system. }\end{array}$ & $\begin{array}{l}\text { Focusing on disease prevention and health } \\
\text { management, this model emphasize providing } \\
\text { patients successive service, establishing long-term } \\
\text { trust relationship between doctors and patients, and } \\
\text { build Team-oriented medical service and } \\
\text { cooperation }\end{array}$ \\
\hline \multirow{3}{*}{ Means } & $\begin{array}{l}\text { Dual referral } \\
\text { system }\end{array}$ & $\begin{array}{l}\text { Cure ailments in communities, } \\
\text { serious illnesses in hospitals and } \\
\text { go back to community for } \\
\text { rehabilitation. }\end{array}$ & $\begin{array}{l}\text { Divide patient from hospital to community. } \\
\text { Accelerate division of labor and cooperation of } \\
\text { hospital and community. It is an effective mean for } \\
\text { horizontal integration of medical resource. }\end{array}$ \\
\hline & $\begin{array}{l}\text { Regional } \\
\text { medical }\end{array}$ & $\begin{array}{l}\text { Sharing, saving and exchanging } \\
\text { health information resource in a } \\
\text { region }\end{array}$ & $\begin{array}{l}\text { Enhance quality and efficiency of medical service. } \\
\text { Save limited resources. Provide better service to the } \\
\text { public and the integration info-net work of } \\
\text { government. }\end{array}$ \\
\hline & Tele-health & $\begin{array}{l}\text { Take usage of new information } \\
\text { technology such as } \\
\text { Telecommunication technology. } \\
\text { Provide remote information and } \\
\text { medical service to regions with } \\
\text { poor condition. }\end{array}$ & $\begin{array}{l}\text { Benefit rural and remote area in wide range, such } \\
\text { as supplying superior resource to hospitals, making } \\
\text { treatment to patient under high-level guidance, } \\
\text { expanding horizons of health workers and reducing } \\
\text { cost of patient }\end{array}$ \\
\hline
\end{tabular}

\section{Discussion of sharing models}

As there are numerous administrative regions in our country, and the developing gap of medical information technology and economic power among the regions are big, it is tough to solve the problem of medical resource disequilibrium with an uniform approach. Depending on this, we proposal promoting medical information construction and model reform basing on existing resource and level of informatization of regions so as to improve equality in health area nationwide.

The eastern coastal developed districts-encourage individualizing and exploration development. As the eastern coastal developed districts have favorable economic condition and advanced concepts, government pay more attention and invest more capital to medical area. Thus some of cities in these districts emphasize on medical information construction and resource integration before the national health reform. There are examples as follow: Before 2006 electronic health records has popularly applied in Shanghai, so as to sharpen the competitive edge, improve the medical quality and reduce cost. In addition, all the tertiary hospitals, a majority of the second-class hospitals and some of the first-level hospitals had equipped HIS by then [4]. Till now , many cites has come into maturity stage in medical information construction, and formed individual developing model. In Shenzhen regional health informatization, based on Electronic Health Record, has established [5]. In Xiamen the military and civilian collaborative demonstration project and medical services is awarded as the most successful practical model of regional medical informatization in China. The Xiamen model realized not only digital integrated platform and medical private network, but unitization of data center and electronic health record as well[6]. 
Suzhou explored new sharing model with taking the health department as the center, which has break the traditional model of segmentation of trap and block. The model of department guiding with third party platform assist opens up a new choice for sharing medical resource[7].

Experts and scholars in health area has been advocating importance of enhancing top-level design and building information criteria. But there are numerous administrative regions in our country and the difference of political and economical environment is large, thus building an ideal top-level is a long process, which should be improved and strengthened with practicing. Therefore, it is significant to sustain exploring reform in eastern coastal developed districts, as the experience provides lessons for the building of top-level design and information criterion. Meanwhile the successful experience can be directly applied in middle area.

Middle area-follow the pace of reform. Under the background of national medical reform, middle area has make great advances, especially in the pilot cities and hospitals. Yet the restriction of economical factors and political factors lead to lot of problems. Hospital leaders lack of internal impetus, and the reform rely on government funding, thus the reform is all pushed by the government. What is more, the reform in pilot cities and hospitals are isolated without active interaction and the system developing from small software suppliers made the transaction and sharing of information have social and technical barriers. That is why the medical establishments are still information islands after reform and why inheritable of the pilot projects. Though progress in scattered hospitals is obvious, regional collaboration health-care is advancing with many obstacles such as, economic interest conflict of hospitals in dual referral, influence to information sharing from lacking of top-level design and criterion, contradiction of the health insurance policy and new rural cooperative medical system. All these are barriers to medical resource sharing.

Middle area should refer to successful experience of eastern coastal developed districts and take regional health as aims, combing with dual referral, so as to remit awkward situation of overcrowding and difficult problem of register in major hospitals. Gradually establish regional resident health records, and integrate existed medical systems such as new rural cooperative medical information management system, medical insurance system, public health management system and community management system [8].

Western area-take tele-medicine as breakthrough. In western area the economic backwardness restrict local development of health seriously, which is still in the stage of primary level. Lacking of capital, the information infrastructure construction in cities and towns is under-investment, and the condition in rural area is even worse---some countries even run without infrastructure construction. What is more, rural area is in short of information workers, and the inconvenience of transportation and communication make the training difficult, which lead to difficulty of construction, renewal and maintain of information facility. At the same time, health workers in rural area have low information technological quality and peasants refuse to accept informatization. All these factors block the information construction of western area under the pace of national program, if imposed the progress under the national schedule, not only enormous pressure would be exerted on national and local economy, but the health workers and residents would be misunderstand and inpatient as well.

Regarding successful examples in developed countries as follows: Remote medical network covered all regions of Canada which country has the condition of vast territory with population dispersion like Chinese western area. And in Austraila, which country share the same geographic condition like western area does, tele-health is extensively used. Lacking of information infrastructure makes the construction of health information platform and regional health networks a harsh task. However, the opening up of the Golden Meditech and application of satellite communication system technology in tele-health point a direction to the balance of medical resource. Distant education can not only resolve the re-education of health workers in western remote area, but can also help the usage and maintain of information equipment and promote spreading of medical knowledge among patients. Remote consultation and tele-operation relieves pressure of low medical level in western area. Thus it is significant to carried out tele-health widely, and take it as the breakout of medical informatization construction in western area. 


\section{References}

[1] Zhu Fenhua, Zhai Miao. A statistical analysis on the allocation of regional health resources in China[J]. Journal of Heze University, 2014.

[2] Zhang Nan, Sun Xiaojie, cheng. Analyzing the equity of health resources allocation in China based on Theil Index[J]. The Chinese Health Service Management, 2014.

[3] Han Xuemei, Jia Dengxun. Analysis on the fairness of healthcare resource allocation in Gansu province[J]. Journal of Lanzhou University(Social Science), 2013.

[4] Yang Jianzheng. Application social security card and electronic signature to promote development of informatization in Shanghai[C].China Seminar and Exhibition of Electronic Medical Record and Digital Hospital Application Technology and Development . 2006.

[5] Luo lexuan Lin denan, Zhu yuanyan. Practice of regional health information in Shenzhen[J]. Chinese Journal of Hospital Administration, 2012

[6] Pang Tao. Xia Men model_—A practical blueprint of regional health information[J]. China Information Times: e-medical, 2013.

[7] Wang Shuai, Su Wei. The current situation and existing problems for the Chinese regional medical information and its corresponding strategies[J]. Modern Preventive Medicine,2010.

[8] Liu Chunfu. Combing information sharing and dual referral in regional medical model[J]. Observation and Thoughts, 2012. 